\title{
Asymmetric Induction in the Arenethiolatocopper(I)-Catalyzed Substitution Reaction of Grignard Reagents with Allylic Substrates
}

\author{
Gerrit J. Meuzelaar, ${ }^{\mathrm{a}}$ A. Sofia E. Karlström, ${ }^{\mathrm{a}}$ Mayra van Klaveren, ${ }^{\mathrm{b}}$ Eva S. M. Persson, \\ Amaya del Villar, ${ }^{\mathrm{b}}$ Gerard van Koten ${ }^{\mathrm{b}, *}$ and Jan-E. Bäckvall ${ }^{\mathrm{a}, *}$ \\ ${ }^{a}$ Department of Organic Chemistry, Arrhenius Laboratory, Stockholm University, SE-106 91 Stockholm, Sweden \\ ${ }^{\mathrm{b}}$ Debye Institute, Department of Metal-Mediated Synthesis, Utrecht University, Padualaan 8, 3584 CH Utrecht, The Netherlands
}

Received 13 December 1999; accepted 10 January 2000

\begin{abstract}
The influence of some experimental parameters on the regio- and enantioselectivity in the $\gamma$-selective substitution reaction of Grignard reagents $\mathrm{RMgX}$ with acyclic allylic acetates catalyzed by the arenethiolatocopper(I) complex $(S)$-1 was studied. When more bulky arenethiolatocopper(I) complexes than $(S)$-1 were employed in a reaction of allylic acetate $\mathbf{3}$ with $n$-BuMgI, the enantioselectivities observed for the $\gamma$-product were lower. With an arenethiolatocopper(I) catalyst prepared in situ, several Grignard reagents were studied in a substitution reaction with acetate 2 . Compared to $n$-BuMgI, more bulky Grignard reagents gave no improvement of the enantioselectivity in the formation of the $\gamma$-product. (C) 2000 Elsevier Science Ltd. All rights reserved.
\end{abstract}

Metal-mediated carbon-carbon bond formation has become a versatile synthetic methodology in contemporary organic chemistry. ${ }^{1}$ Copper-catalyzed reactions constitute an important class, and well-known examples include Michael addition reactions and cross-coupling reactions of organometallic reagents with organic halides or allylic substrates. ${ }^{2}$ The allylic substitution reaction has attracted much attention and several methods have been developed for control of the regio- and stereochemistry in this type of reactions. ${ }^{3-6}$ The leaving group can be displaced either in an $\alpha\left(\mathrm{S}_{\mathrm{N}} 2\right)$ or $\gamma$ $\left(\mathrm{S}_{\mathrm{N}} 2^{\prime}\right)$ fashion by the organometallic reagent (Scheme 1$)$.
Although asymmetric induction in copper-promoted Michael additions to $\alpha, \beta$-unsaturated systems is quite well established, ${ }^{7-9}$ the corresponding enantioselective versions of organocopper-based allylic substitution reactions are less developed. Asymmetric $\mathrm{S}_{\mathrm{N}} 2^{\prime}$ substitution of allylic substrates with a chiral leaving group by organocuprates has been reported ${ }^{10}$ but catalytic procedures employing chiral ligands on copper are scarce. ${ }^{11,12}$ In 1995, we described the first example on the use of a chiral copper(I) complex as a catalyst in the cross-coupling of Grignard reagents with allylic substrates. ${ }^{11}$ E.e.'s up to $42 \%$ were

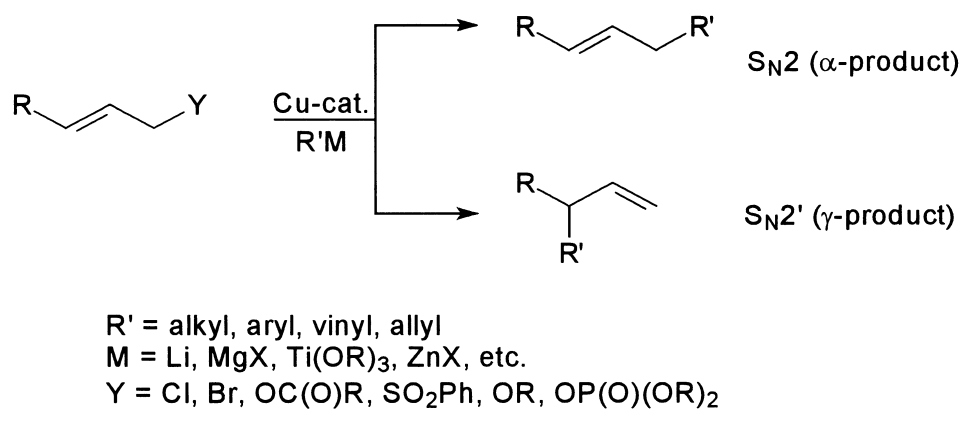

Scheme 1. Copper-catalyzed allylic substitution reactions.

Keywords: asymmetric induction; copper catalysis; allylic substitution; cross-coupling.

* Corresponding authors. Tel.: +46-8-6747178; fax: +46-8-154908; e-mail: jeb@organ.su.se 


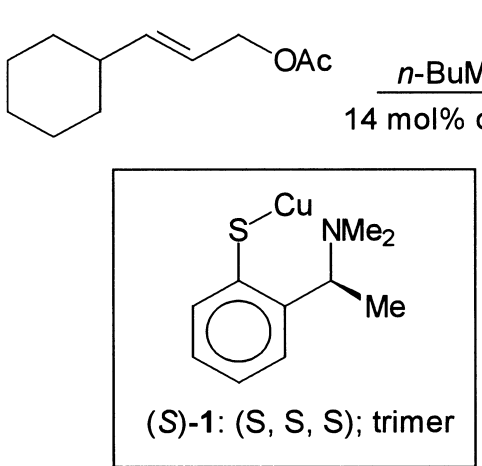<smiles>C=CC(Br)C1CCCCC1</smiles>

complete $\gamma$-selectivity

$42 \%$ e.e.

Scheme 2. An asymmetric allylic substitution reaction catalyzed by a chiral arenethiolatocopper(I) complex.

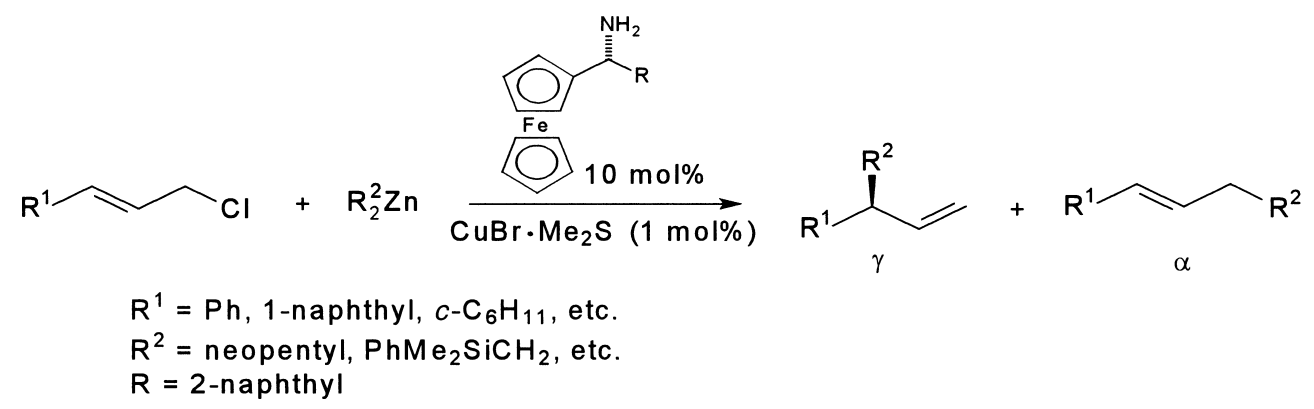

Scheme 3. Copper(I)-catalyzed asymmetric allylic substitution reactions according to Dübner and Knochel. ${ }^{12}$

obtained in the reaction of allylic acetates with $n$-BuMgI catalyzed by chiral arenethiolatocopper(I) complex $(S)-\mathbf{1}$ (Scheme 2). Recently, chiral ferrocenyl amine ligands were employed in copper-catalyzed enantioselective substitution of allyl chlorides with diorganozinc compounds (Scheme 3). ${ }^{12}$ The alkylated products were obtained in up to $87 \%$ e.e. with good $\mathrm{S}_{\mathrm{N}} 2^{\prime}$ selectivity but the reaction is limited to sterically hindered dialkylzinc reagents.

In addition to our earlier work with $(S)$-1 as a catalyst, ${ }^{11}$ we now wish to report on a more detailed study of the asymmetric cross-coupling reaction of Grignard reagents $\mathrm{R}^{\prime} \mathrm{MgX}$ with acyclic allylic substrates $\mathrm{RCH}=\mathrm{CHCH}_{2} \mathrm{Y}$, catalyzed by this type of copper complexes. We have further investigated the experimental parameters for these reactions. Various Grignard reagents $\mathrm{R}^{\prime} \mathrm{MgX}$ have been investigated in the allylic substitution reactions as well as the influence of different arenethiolato ligands in the catalyst. We also include the results obtained with a catalyst prepared in situ from an arenethiol and a copper salt under various conditions.

\section{Results and Discussion}

\section{Reactions with preformed arenethiolatocopper(I) complexes}

We started our investigations with arenethiolatocopper(I) complex $(S)$-1 which was prepared from $(-)-(S)$ - $\alpha$-methylbenzylamine according to a literature procedure. ${ }^{13}$ It was previously shown that the regioselectivity of the reaction between geranyl acetate and $n$-BuMgI catalyzed by an achiral arenethiolatocopper(I) complex can be tuned to either $\alpha$ or $\gamma$ substitution by variation of the reaction conditions (Scheme 4). ${ }^{14}$ For the present study, using $(S)-\mathbf{1}$, the $\gamma$-selective reaction conditions were chosen. Thus, the reactions were performed in diethyl ether at $0^{\circ} \mathrm{C}$. The
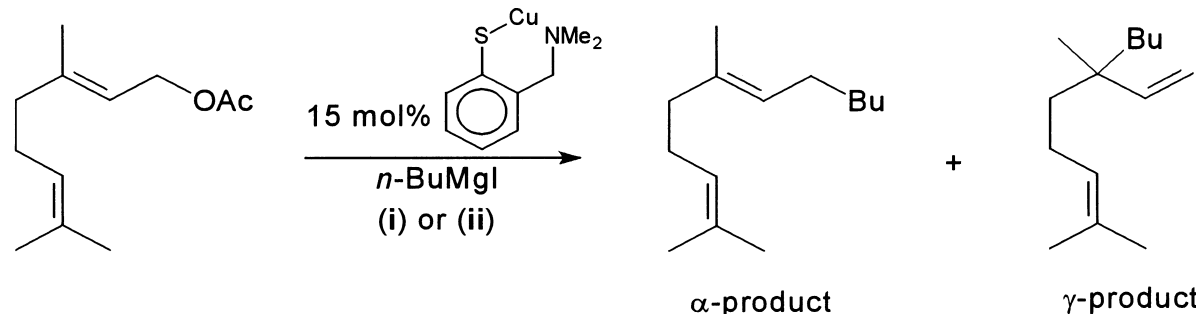

Scheme 4. Selectivity for either the $\alpha$ - or $\gamma$-product in an allylic substitution reaction of geranyl acetate by varying the reaction conditions: $(\mathbf{i})$ : Et ${ }_{2} \mathrm{O}, 0^{\circ} \mathrm{C}$, $120 \mathrm{~min}$ addition time of $n$-BuMgl, $100 \% \gamma$-product; (ii): THF, $-30^{\circ} \mathrm{C}, 5$ min addition time of $n$-BuMgl, $100 \% \alpha$-product. 
Table 1. Influence of the addition method and the Grignard reagent (n.det.=not detected)
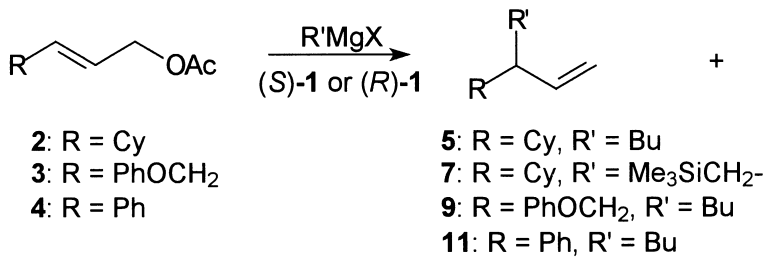
$\mathrm{R}^{\mathrm{R}}$
6: $R=C y, R^{\prime}=B u$
8: $\mathrm{R}=\mathrm{Cy}, \mathrm{R}^{\prime}=\mathrm{Me}_{3} \mathrm{SiCH}_{2-}$
10: $\mathrm{R}=\mathrm{PhOCH}_{2}, \mathrm{R}^{\prime}=\mathrm{Bu}$
12: $R=P h, R^{\prime}=B u$

\begin{tabular}{|c|c|c|c|c|c|c|c|c|}
\hline Entry & Substrate & $\mathrm{R}^{\prime} \mathrm{MgX}$ & $\operatorname{Mol} \% \mathbf{1}^{\mathrm{a}}$ & $\mathrm{AM}^{\mathrm{b}}$ & Yield $(\%)^{\mathrm{c}}$ & $\alpha: \gamma$ Ratio $^{\mathrm{d}}$ & E.e. of $\gamma(\%)^{\mathrm{e}}$ & {$[\alpha]_{\mathrm{D}}\left({ }^{\circ}\right)^{\mathrm{e}}$} \\
\hline 1 & 2 & $n$-BuMgI & $15(\boldsymbol{R})$ & A & $100(88)$ & $0: 100$ & $41(5)$ & -4.5 \\
\hline 2 & 2 & n-BuMgI & $100(\boldsymbol{S})$ & A & 100 & $0: 100$ & $45(5)$ & +4.8 \\
\hline 3 & 2 & $n$-BuMgBr & $15(\boldsymbol{R})$ & $\mathrm{A}$ & $(67)^{f}$ & $0: 100$ & $50(5)^{g}$ & -4.9 \\
\hline 4 & 2 & $\mathrm{Me}_{3} \mathrm{SiCH}_{2} \mathrm{MgI}$ & $15(\boldsymbol{R})$ & A & $(30)^{\mathrm{f}}$ & $0: 100$ & $53(7)$ & n.det. \\
\hline 5 & 2 & $n$-BuMgI & $14(S)$ & $\mathrm{C}$ & 100 & $0: 100$ & $42(5)$ & +4.4 \\
\hline 6 & 2 & $n$-BuMgI & $20(S)$ & $\mathrm{C}$ & 100 & $0: 100$ & $41(5)$ & +4.3 \\
\hline 7 & 3 & $n$-BuMgI & $13(S)$ & $\mathrm{A}$ & 100 & $0: 100$ & $34(9)$ & n.det. \\
\hline 8 & 3 & $n$-BuMgI & $15(S)$ & $\mathrm{B}$ & 100 & $0: 100$ & $18(9)$ & n.det. \\
\hline 9 & 3 & $n$-BuMgI & $13(S)$ & $\mathrm{C}$ & 100 & $0: 100$ & $30(9)$ & n.det. \\
\hline 10 & 4 & $n$-BuMgI & $15(\boldsymbol{R})$ & A & 100 & $0: 100$ & $28(\mathbf{1 1})$ & -10.5 \\
\hline
\end{tabular}

${ }^{\text {a }}$ Amount of $\mathbf{1}$ based on monomeric copper units.

${ }^{\mathrm{b}} \mathrm{AM}=$ addition method; Method A: The Grignard reagent (1.25 equiv.) was added to a solution of $\mathbf{1}$ and allylic substrate ( 1 equiv.) in diethyl ether at $0^{\circ} \mathrm{C}$. Method B: The allylic acetate (1 equiv.) was added slowly to a solution of 1 and $n$-BuMgI (1.25 equiv.) in diethyl ether at $0^{\circ} \mathrm{C}$. Method C: The allylic acetate and $n$-BuMgI were added separately within $120 \mathrm{~min}$ to a solution of 1 in diethyl ether at $0^{\circ} \mathrm{C}$.

${ }^{\mathrm{c}}$ Unless otherwise stated; substrate 2: yield of $\mathbf{5}$ determined by GC and ${ }^{1} \mathrm{H}$ NMR. Substrate $\mathbf{3}$ or $\mathbf{4}$ : yield of $\mathbf{9}$ or $\mathbf{1 1}$ determined by GC. Isolated yields in parentheses.

d $\alpha: \gamma$ ratio determined by GC.

${ }^{\mathrm{e}}$ E.e. of 5 determined by optical rotation $\left([\alpha]_{\mathrm{D}}=-9.4\right.$ corresponds to $88 \%$ e.e. of $R$-enantiomer $\left.{ }^{10 \mathrm{a}}\right)$. E.e. of $\mathbf{9}$ determined by HPLC. E.e. of 7 and $\mathbf{1 1}$ determined by GC.

${ }^{\mathrm{f}}$ Only isolated yield was determined.

${ }^{g}$ The e.e. was determined by GC. The e.e. determined by optical rotation was $46 \%$. In all cases GC analysis gave somewhat higher e.e. values than obtained by measuring the optical rotation.

influence of some reaction parameters on the yield and asymmetric induction of the $\gamma$-product was then studied with the use of allylic acetates $\mathbf{2}, \mathbf{3}$ and $\mathbf{4}$ (Table 1).

The order of addition of the Grignard reagent and the allylic acetate has an influence on the outcome of the reaction (Table 1). Three different addition methods were studied. The Grignard reagent was added slowly (120 $\mathrm{min})$ to a solution of the catalyst and the substrate $(\operatorname{method} \mathrm{A})$, or the substrate was added slowly to a solution of the catalyst and the Grignard reagent (method B). In a third addition method the substrate and the Grignard reagent were added separately, at the same rate, to the reaction mixture (method C). Methods A and C investigated with (E)-3-cyclohexyl-2propenylacetate $(2)^{4 \mathrm{~d}}$ resulted in all cases in regioselective formation of the $\gamma$-product (Entries 1-6). Both methods afforded $\gamma$-product 5 with a significant e.e., $42 \%$ e.e. with method $\mathrm{C}$ and $41 \%$ e.e. with method $\mathrm{A}$, respectively. The e.e. obtained with method A could be improved to $45 \%$ by using one equivalent of (S)-1 (Entry 2). When $n$ - BuMgBr was employed instead of $n$-BuMgI, the e.e. increased to $50 \%$ (Entry 3). The substitution reaction with the bulky $\mathrm{Me}_{3} \mathrm{SiCH}_{2} \mathrm{MgI}$ gave $\gamma$-product 7 with $53 \%$ e.e (Entry 4 ). However, the yield of $\mathbf{7}$ in the latter case was low due to

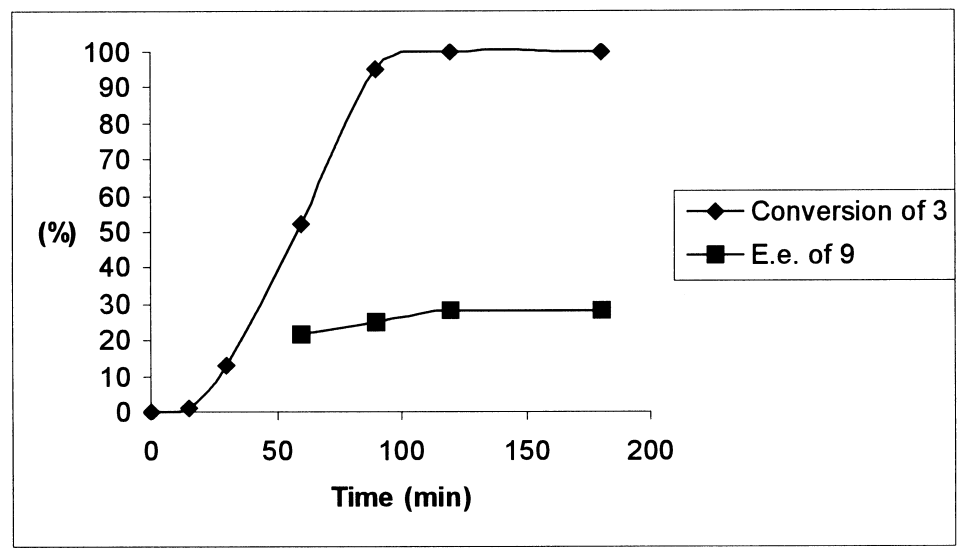

Figure 1. Reaction time vs. conversion of $\mathbf{3}$ and e.e. of $\mathbf{9 .}$ 


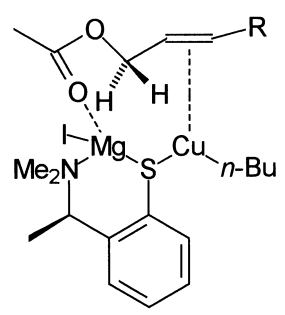

Figure 2. Proposed intermediate in arenethiolatocopper(I)-catalyzed substitution reactions of allylic acetates.

incomplete conversion of $\mathbf{2}$. With $(E)$-1-acetoxy-4-phenoxy2-butene $(3)^{4 \mathrm{~b}, 15}$ as substrate, all three methods afforded $\gamma$-product 9 with complete chemo- and regioselectivity (Entries 7-9). Methods A and C proved to be superior to method B which gave the same regioselectivity, but a lower enantioselectivity (Entry 8). Since the results obtained with methods $\mathrm{A}$ and $\mathrm{C}$ are almost equal, the experimentally easier addition method $\mathrm{A}$ was used exclusively in the further experiments.

Both substrates $\mathbf{2}$ and $\mathbf{3}$ gave the substitution product with complete $\gamma$-selectivity and a similar enantioselectivity. In order to study the influence of the substituent $\mathrm{R}$ in more detail, we employed trans-cinnamyl acetate (4) as substrate. Compounds of this type are of special interest since it is known that a conjugated double bond in the allylic substrate favors formation of the $\alpha$-product $\left(\mathrm{S}_{\mathrm{N}} 2\right.$-substitution). ${ }^{16}$ However, the reaction between 4 and $n$-BuMgI using addition method A with $15 \mathrm{~mol} \%$ of $(R)-\mathbf{1}$ as catalyst resulted in complete conversion to the $\gamma$-substitution product 3-phenyl-1-heptene (11) which was formed with $28 \%$ e.e.
Using addition method $\mathrm{A}$, we followed the progress of the reaction of 3 with $n$-BuMgI catalyzed by $15 \mathrm{~mol} \%$ of complex $(S)$-1. Samples of the reaction mixture were collected at regular time intervals and the conversion of $\mathbf{3}$ and the e.e. of $\gamma$-product 9 were determined. The results are presented in Fig.1. At the beginning the reaction is slow and only $1 \%$ conversion of $\mathbf{3}$ is obtained after $15 \mathrm{~min}$. However, after about $20 \mathrm{~min}$, the reaction becomes faster and the conversion then increases approximately linearly with time. The reaction reaches completion after $120 \mathrm{~min}$. The e.e. of 9 increases from $22 \%$ after 60 min addition time, to $28 \%$ after $120 \mathrm{~min}$ addition time. The results indicate that catalysis does not really start until at least one equivalent (or may be even two equivalents) of the Grignard reagent is present relative to the amount of catalyst, i.e. the keyintermediate will at least have one molecule of Grignard reagent bound per copper center. The allylic acetate will then coordinate preferably with either the re or the si-face of the double bond to give the earlier proposed catalytic intermediate (Fig. 2). ${ }^{11}$

In order to investigate the influence of the chiral ligand in the copper-catalyzed allylic substitution reactions, different arenethiolatocopper(I) complexes (Fig. 3) were prepared and tested in the reaction of acetate 3 with $n$-BuMgI. Complex 13 (tetramer) was prepared starting from $(+)-(R)-\alpha$-methylbenzylamine via monomethylation of the amine moiety followed by introducing the methoxy-arm according to a literature procedure. ${ }^{13 \mathrm{c}}$ Complex 14 was prepared starting from $(+)-(R)-\alpha$-ethylbenzylamine (e.e. $90 \%$ ), obtained by the enantioselective addition of diethyl zinc to benzaldehyde followed by conversion of the hydroxyl group into an amine function by standard methods. ${ }^{17}$ The synthesis of complex $\mathbf{1 5}$ was performed in an analogous way

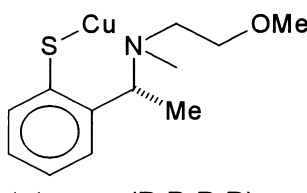

tetramer $(R, R, R, R)$

13<smiles>CCC(CC)c1ccccc1SC</smiles>

14<smiles>[R][R]([R])[C@@H](C)c1ccccc1SC</smiles>

15

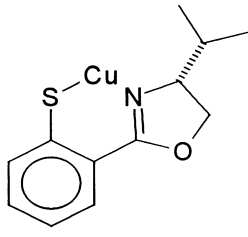

16

Figure 3. Chiral arenethiolatocopper(I) complexes applied in asymmetric substitution reactions of $\mathbf{3}$.

Table 2. Substitution reactions of $\mathbf{3}$ catalyzed by different types of chiral arenethiolatocopper(I) complexes (method A: $n$-BuMgI (1.25 equiv.) added within $120 \mathrm{~min}$ to a solution of $\mathbf{3}$ ( 1 equiv.) and $15 \mathrm{~mol} \%$ of copper(I) complex (based on monomeric copper units) in $\mathrm{Et}_{2} \mathrm{O}$ at $0^{\circ} \mathrm{C}$ )

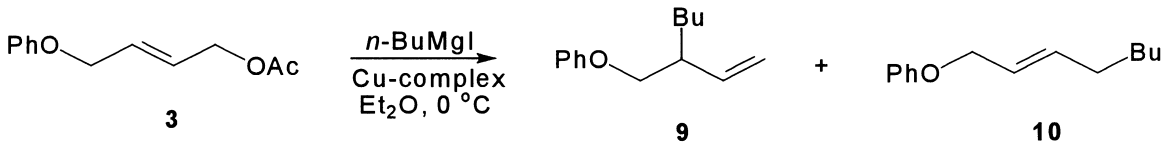

\begin{tabular}{|c|c|c|c|c|c|}
\hline Entry & Cu-complex & Conversion $(\%)^{\mathrm{a}}$ & Yield of $\mathbf{9}+\mathbf{1 0}(\%)^{\mathrm{a}}$ & $\alpha: \gamma(10: 9)$ Ratio $^{a}$ & E.e. of $9(\%)^{\mathrm{b}}$ \\
\hline 1 & $(S)-1$ & 100 & 100 & $0: 100$ & 34 \\
\hline 2 & 13 & 100 & 95 & $5: 95$ & 4 \\
\hline 3 & 14 & 100 & 100 & $0: 100$ & 12 \\
\hline 4 & 15 & 100 & $86^{c}$ & $0: 100$ & 13 \\
\hline 5 & 16 & 95 & 95 & $2: 98$ & 0 \\
\hline
\end{tabular}

${ }^{\mathrm{a}}$ Conversion, yield and $\alpha: \gamma$ ratio determined by GC and ${ }^{1} \mathrm{H}$ NMR.

${ }^{\mathrm{b}}$ E.e. determined by HPLC.

${ }^{\mathrm{c}}$ Isolated yield after purification by column chromatography. 


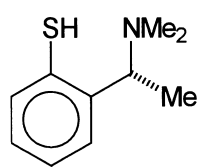

17

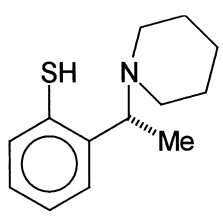

18

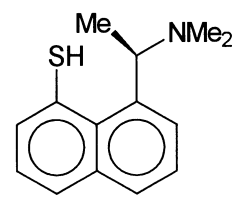

19

Figure 4. Structure of the ligands employed in the in situ preparation of arenethiolatocopper(I) catalysts.

as described for $(S)-\mathbf{1}^{13 \mathrm{c}}$ The intermediates were synthesized in accordance with a literature procedure. ${ }^{17 \mathrm{~b}}$ The structure of $\mathbf{1 5}$ was determined by X-ray crystallography and was found to consist of trimeric units. ${ }^{18}$ The arenethiolatocopper(I) complex 16, with a chiral isopropyl containing oxazoline moiety, was prepared according to a literature procedure starting from $(-)-(S)$-valinol. ${ }^{19}$

Table 2 shows the results obtained with these catalysts. Whereas complex $(S)$-1 gave the $\gamma$-product with complete selectivity in $34 \%$ e.e. (Entry 1), complex 13 gave the substitution product in an $\alpha: \gamma$ ratio of 5:95 (10:9) with only $4 \%$ e.e. for the $\gamma$-product (Entry 2). Complex 14, with an ethyl group at the chiral carbon center, gave a selective formation of the $\gamma$-product with an e.e. of $12 \%$ (Entry 3). Complex 15, with a pyrrolidine ring, also gave a completely $\gamma$-selective reaction. However, the e.e. of the $\gamma$-product was low (13\%). The oxazoline substituted arenethiolatocopper(I) catalyst $\mathbf{1 6}$ gave $95 \%$ conversion of the substrate and the substitution product was formed with an $\alpha: \gamma$ ratio of $2: 98(\mathbf{1 0 : 9})$. However, the $\gamma$-product was found to be racemic. The results clearly show that all investigated complexes give the substitution product with high $\gamma$-selectivity, but complexes 13-16 all give lower asymmetric inductions than $(S)-\mathbf{1}$ for the studied reaction.

\section{Reactions with arenethiolatocopper(I) complexes prepared in situ}

The arenthiolatocopper(I) complexes described above are highly air-sensitive compounds and are therefore not easy to prepare, store and handle. We therefore turned to the possibility of performing the allylic substitution reactions with arenethiolatocopper(I) catalysts prepared in situ from the corresponding arenethiols and a copper(I) source. This approach has been reported earlier by Pfaltz and co-workers. ${ }^{19}$ Thus, treatment of arenethiol $17^{13 \mathrm{~b}}$ (Fig. 4) with $n$-BuLi yields the lithium arenethiolate. Subsequent reaction with a copper(I) source gives $(R)-\mathbf{1}$. Addition of the allylic substrate and a Grignard reagent to this reaction mixture leads to the desired reaction. One difference to the preformed catalyst system is that the in situ prepared catalyst will contain one equivalent of lithium salt, which could have an effect on the reaction. We have performed various reactions of allylic substrates $\mathbf{2}$ and $\mathbf{4}$ using catalysts prepared in situ to study the influence of different experimental parameters such as the copper source and the Grignard reagent.

The reaction of $\mathbf{2}$ with $n$-BuMgI, using the catalyst generated from 17 and CuI, resulted in selective formation of the $\gamma$-product (Table 3, Entry 1). The e.e. was almost the same as that observed with the preformed catalyst (40 and
$42 \%$ e.e., respectively). The presence of one equivalent of lithium iodide seems to have no influence on the outcome of the reaction. An increase of temperature from 0 to $20^{\circ} \mathrm{C}$ did not change the enantioselectivity (Entry 2). The same effect was observed with the preformed catalyst. ${ }^{11}$ With two equivalents of ligand, no significant change of the e.e was found (Entry 3), indicating that one ligand molecule is strongly bound to the copper atom in the catalytic intermediate. A control experiment with $\mathrm{CuI}$ as catalyst, in the absence of ligand, gave an incomplete conversion of $\mathbf{2}$ (Entry 4). The $\gamma$-selectivity was still high $(\alpha: \gamma=5: 95)$, but beside the substitution products the alcohol 3-cyclohexyl( $2 E$ )-propenol, formed by attack of the Grignard reagent on the ester carbonyl group, and other unidentified products were observed. This leads to the conclusion that the arenethiolate ligand is necessary for a fast and efficient $\gamma$-selective substitution reaction.

We also investigated the influence of the copper source on the outcome of the substitution reaction. With $\mathrm{CuCl}$ and $\mathrm{Cu}(\mathrm{OTf})_{2}$ the conversion of $\mathbf{2}$ was complete and only the $\gamma$-substitution product was formed (Entries 5 and 6). The reaction with $\mathrm{Cu}(\mathrm{OTf})_{2}$ as copper source showed a lower e.e. for the $\gamma$-product. From this copper salt the active copper(I) species is formed by in situ reduction by the Grignard reagent. The fact that $\mathrm{CuI}$ and $\mathrm{CuCl}$ both result in formation of the $\gamma$-product with the same e.e. supports the proposal that the lithium halide present in the reaction mixture has no influence on the outcome of the reaction. With $\mathrm{CuBr} \cdot \mathrm{Me}_{2} \mathrm{~S}$ the conversion and the e.e. of the $\gamma$-product were much lower (Entry 7 ). This is probably caused by the coordinated dimethyl sulfide which hampers formation of the catalytic intermediate (Fig. 2). Replacement of the iodide in the Grignard reagent by bromide had a negative influence on the outcome of the substitution reaction. With $n$ - $\mathrm{BuMgBr}$ the reaction was not completely $\gamma$-selective and the e.e. of the $\gamma$-product was lower (Entry $8)$. This is in contrast to the reaction with $n-\mathrm{BuMgBr}$ in the presence of the preformed copper complex which gave the $\gamma$-product with $50 \%$ e.e. (Table 1 ). Replacement of $\mathrm{CuI}$ by $\mathrm{CuBr}$ as copper source gave the $\gamma$-product with a slightly improved e.e. of $36 \%$ (Entry 9). We also investigated ligand $\mathbf{1 8}^{17 \mathrm{~b}}$ (Fig. 4) in the allylic substitution reaction of 2 . Preparation of a preformed copper(I) arenethiolate with this ligand proved to be cumbersome. The catalyst prepared from 18 and $\mathrm{CuI}$ gave complete conversion of $\mathbf{2}$ and the reaction was $\gamma$-selective. However, the e.e. observed for the $\gamma$-product was only $10 \%$ (Entry 10 ).

Ligand 19 (Fig. 4) was prepared from commercially avail-

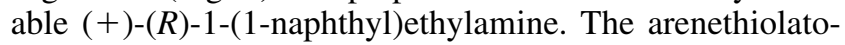
copper catalyst prepared from $\mathbf{1 9}$ gave complete conversion of 2 in a reaction with $n$-BuMgI (Entry 11). The $\alpha: \gamma$ ratio 
Table 3. Substitution reactions of $\mathbf{2}$ and $\mathbf{4}$ catalyzed by arenethiolatocopper(I) complexes prepared in situ (unless otherwise stated the reactions were carried out with a copper(I) complex prepared from arenethiol 17. The Grignard reagent (1.25 equiv.) was added within 120 min to a solution of the allylic acetate ( 1 equiv.) and $15 \mathrm{~mol} \%$ of the copper(I) complex (prepared in situ) in $\mathrm{Et}_{2} \mathrm{O}$ at $0^{\circ} \mathrm{C}$ )

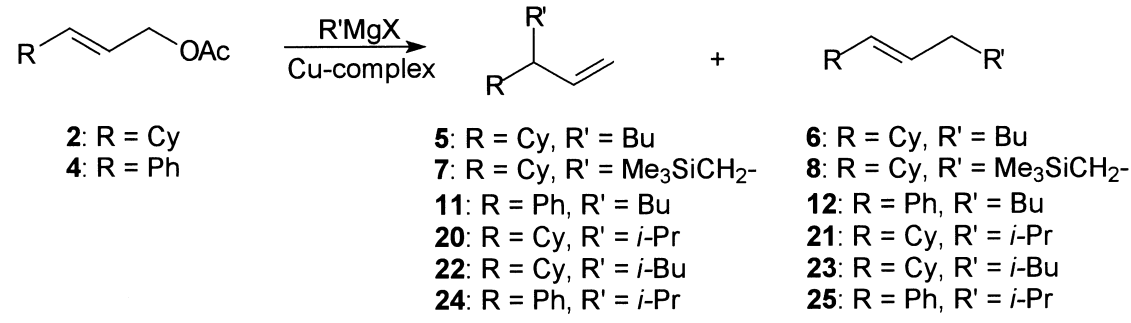

\begin{tabular}{|c|c|c|c|c|c|c|c|}
\hline Entry & Substrate & $\mathrm{R}^{\prime} \mathrm{MgX}$ & Copper salt & $T\left({ }^{\circ} \mathrm{C}\right)$ & Conversion $(\%)^{\mathrm{a}}$ & $\alpha: \gamma$ Ratio $^{\mathrm{a}}$ & E.e. of $\gamma(\%)^{b}$ \\
\hline 1 & 2 & n-BuMgI & $\mathrm{CuI}$ & 0 & 100 & $0: 100$ & 40 \\
\hline 2 & 2 & $n$-BuMgI & $\mathrm{CuI}$ & 20 & 100 & $0: 100$ & 40 \\
\hline $3^{c}$ & 2 & $n$-BuMgI & $\mathrm{CuI}$ & 0 & 100 & $0: 100$ & 39 \\
\hline $4^{\mathrm{d}}$ & 2 & $n$-BuMgI & $\mathrm{CuI}$ & 0 & 65 & $5: 95$ & - \\
\hline 5 & 2 & $n$-BuMgI & $\mathrm{CuCl}$ & 0 & 100 & $0: 100$ & 40 \\
\hline 6 & 2 & $n$-BuMgI & $\mathrm{Cu}(\mathrm{OTf})_{2}$ & 0 & 100 & $0: 100$ & 35 \\
\hline 7 & 2 & n-BuMgI & $\mathrm{CuBr} \cdot \mathrm{Me}_{2} \mathrm{~S}$ & 0 & 60 & $0: 100$ & 7 \\
\hline 8 & 2 & n-BuMgBr & $\mathrm{CuI}$ & 0 & 100 & $8: 92$ & 30 \\
\hline 9 & 2 & $n$-BuMgBr & $\mathrm{CuBr}$ & 0 & 100 & $8: 92$ & 36 \\
\hline $10^{\mathrm{e}}$ & 2 & n-BuMgI & $\mathrm{CuI}$ & 0 & 100 & $0: 100$ & 10 \\
\hline $11^{\mathrm{f}}$ & 2 & $n$-BuMgI & $\mathrm{CuI}$ & 0 & 100 & $3: 97$ & $35^{\mathrm{g}}$ \\
\hline 12 & 2 & $i$-PrMgI & $\mathrm{CuI}$ & 0 & 100 & $0: 100$ & 34 \\
\hline 13 & 2 & $i$-PrMgI & $\mathrm{CuI}$ & -30 & 100 & $0: 100$ & 29 \\
\hline 14 & 2 & $i$-PrMgBr & $\mathrm{CuI}$ & 0 & 100 & $0: 100$ & 14 \\
\hline 15 & 2 & $\mathrm{Me}_{3} \mathrm{SiCH}_{2} \mathrm{MgI}$ & $\mathrm{CuI}$ & 20 & 100 & $0: 100$ & 37 \\
\hline 16 & 2 & $i$-BuMgBr & $\mathrm{CuI}$ & 0 & 80 & $30: 70$ & 40 \\
\hline 17 & 2 & PhMgI & $\mathrm{CuI}$ & $0^{\mathrm{h}}$ & - & - & - \\
\hline 18 & 4 & $n$-BuMgI & $\mathrm{CuI}$ & 0 & 100 & $0: 100$ & 30 \\
\hline 19 & 4 & $i$-PrMgI & $\mathrm{CuI}$ & 0 & 100 & $0: 100$ & 18 \\
\hline 20 & 4 & $i$-PrMgBr & $\mathrm{CuI}$ & 0 & 100 & $0: 100$ & 25 \\
\hline
\end{tabular}

${ }^{\mathrm{a}}$ Conversion and $\alpha: \gamma$ ratio determined by GC. Isolated yields at $100 \%$ conversion: $50-95 \%$.

${ }^{\mathrm{b}}$ E.e. determined by GC.

${ }^{\mathrm{c}}$ Ligand to copper ratio 2:1.

${ }^{\mathrm{d}}$ No ligand added.

e Ligand 18 was employed.

${ }^{\mathrm{f}}$ Ligand 19 was employed.

The $(S)$-enantiomer was formed in excess (see text).

${ }^{\mathrm{h}} \mathrm{No}$ allylic substitution observed. A reaction performed at $20^{\circ} \mathrm{C}$ gave no improvement.

was 3:97 and the e.e. of the $\gamma$-product was $35 \%$. Complex $(R)-\mathbf{1}$ and the complexes prepared from $(R)-\mathbf{1 7}$ or $(R)-\mathbf{1 8}$ always gave $(R)-\mathbf{5}$ in excess. However, the catalyst prepared from $(R)$-19 gave $(S)-5$ in excess. The reason for this change in enantioselectivity is at the moment not clear but further investigations are underway. In this case a seven-membered chelate would be formed instead of the six-membered chelate formed from $(R)-\mathbf{1}$ (cf. Fig. 2).

Since the substitution reactions with $n$-butylmagnesium halides gave the $\gamma$-product with only moderate enantioselectivities we have investigated other, more bulky Grignard reagents. Some results are included in Table 3. It is noteworthy that the secondary Grignard reagents $i$-PrMgI and $i$-PrMgBr can also be employed (Entries $12-14$ ). ${ }^{18,19}$ With all Grignard reagents the $\gamma$-selectivity was complete except for the reaction with $i-\mathrm{BuMgBr}$ (Entry 16). However, the enantioselectivities were always lower than found with the $n$-butyl Grignard reagents. The bulky $\mathrm{Me}_{3} \mathrm{SiCH}_{2} \mathrm{MgI}$ gave the $\gamma$-product with an e.e. not higher than $37 \%$ (Entry 15) which is substantially lower than the enantioselectivity obtained with the preformed catalyst. The reaction with this Grignard reagent had to be carried out at $20^{\circ} \mathrm{C}$. At $0^{\circ} \mathrm{C}$ there was almost no conversion of 2 . The reaction of $\mathbf{2}$ with $\mathrm{PhMgI}$ resulted in recovery of $\mathbf{2}$ and formation of 3 -cyclohexyl-(2E)-propenol (Entry 17). This shows that a copper(I) arenethiolato complex is not a suitable catalyst for reactions with aryl Grignard reagents.

Finally, we studied some reactions of $\mathbf{4}$ with Grignard reagents in the presence of the catalyst prepared in situ from ligand 17 and $\mathrm{CuI}$ (Table 3, Entries 18-20). In all cases the substitution reaction was completely $\gamma$-selective. Again the reaction with $n$-BuMgI gave the $\gamma$-product with a moderate e.e. (30\%, Entry 18$)$.

\section{Conclusions}

We have shown that the outcome of the asymmetric substitution reaction of allylic acetates with Grignard reagents catalyzed by a chiral arenethiolatocopper(I) catalyst depends on the addition procedure of the reactants. Using the most convenient addition method we followed the progress of an allylic substitution reaction in time. At least one equivalent of Grignard reagent relative to the 
amount of copper species is necessary to start the catalytic reaction, which provides further support for our earlier proposed structure of the catalytic intermediate. Varying the chiral ligand in the catalysts showed that any group larger than a methyl group on the amino function lowers the chiral induction in the formation of the $\gamma$-product. Performing the reactions with an arenethiolatocopper(I) catalyst prepared in situ was also possible. Different Grignard reagents were investigated and it was shown that reagents more bulky than $n$-BuMgI gave the $\gamma$-products with the same or with lower enantioselectivity. We are currently investigating various other chiral nitrogen- and sulfur-containing ligands in the copper-catalyzed asymmetric substitution reaction of allylic acetates.

\section{Experimental}

General: Mass spectra were determined using a Thermoquest 2000A GC-MS with a Varian DB-5 column $(15 \mathrm{~m} \times 0.32 \mathrm{~mm}) .{ }^{1} \mathrm{H}(300 \mathrm{MHz})$ and ${ }^{13} \mathrm{C}(75 \mathrm{MHz}) \mathrm{NMR}$ spectra were recorded using a Varian Mercury 300 spectrometer with $\mathrm{CDCl}_{3}$ as solvent using residual $\mathrm{CHCl}_{3}$ (7.26 and $77.0 \mathrm{ppm}$, respectively) as internal standard. The infrared spectrum of 19 was recorded using a Perkin-Elmer Spectrum One spectrophotometer. The e.e. was determined either with analytical HPLC using a Chiralcel OD-H column (eluent: 99-99.5\% hexane, 0.5-1\% 2-propanol, compound 9) or $\mathrm{GC}$ using a CP-Chirasil-Dex $\mathrm{CB}$ column $\left(70^{\circ} \mathrm{C}\right.$ isotherm). Optical rotations were measured using a Perkin-Elmer 241 polarimeter at the sodium D line $(\lambda=589 \mathrm{~nm})$. Merck silica gel (Silica 60, 230-400 mesh) was used for flash column chromatography. TLC was performed on deactivated silica $\left(0.25 \mathrm{~mm}\right.$, Merck $\left.\mathrm{F}_{254}\right)$. All reactions were run under a dry argon or nitrogen atmosphere. Diethyl ether was dried over Na-benzophenone prior to use. Grignard reagents were made according to standard procedures and titrated before use. ${ }^{20}$ trans- $^{-}$ Cinnamyl acetate (4) was purchased from Lancaster and used without further purification. $(+)-(R)-\alpha$-Methylbenzylamine (e.e. 99\%) was purchased from Acros. (+)- $(R)-$ Naphthylethylamine was purchased from Lancaster. $(E)-3$ Cyclohexyl-2-propenylacetate $(2)^{4 \mathrm{~d}}$ and $(E)$-1-acetoxy-4phenoxy-2-butene $(\mathbf{3})^{4 \mathrm{~b}, 15}$ were prepared according to literature procedures. The spectral data were consistent with those previously reported. The copper complexes $\mathbf{1},{ }^{13 \mathrm{c}} \mathbf{1 3},{ }^{13 \mathrm{c}} \mathbf{1 4},{ }^{17} \mathbf{1 5},{ }^{13 \mathrm{c}, 17}$ and $\mathbf{1 6}^{19}$ and the arenethiols $\mathbf{1 7}^{13 \mathrm{~b}}$ and $18^{17 \mathrm{~b}}$ were prepared according to literature procedures. The NMR data of 1, 13, 16, 17 and 18 were consistent with those reported in the references.

\section{Synthesis of the arenethiol ligands}

(R)-(2-Piperidino)-2-ethyl-1-benzenethiol (18). Compound 18 was prepared according to Ref.17b, but a modified workup procedure was used. After addition of conc. $\mathrm{HCl}$ (aq.), all volatiles were evaporated. The residue was dissolved in $\mathrm{CH}_{2} \mathrm{Cl}_{2}$ and filtrated through a short column of silica. The solvent was evaporated in vacuo and the crude product was crystallized from $\mathrm{CH}_{2} \mathrm{Cl}_{2}$ by addition of $\mathrm{Et}_{2} \mathrm{O}$. The resulting white needle-shaped crystals were washed with $\mathrm{Et}_{2} \mathrm{O}$ and dried in vacuo to yield $31 \%$ of $\mathbf{1 8}$. The NMR data were in accordance with those reported except that all signals in the
${ }^{1} \mathrm{H}$ NMR spectrum $\left(\mathrm{CD}_{3} \mathrm{OD}\right)$ should be shifted $1.45 \mathrm{ppm}$ downfield.

8-(1-Dimethylaminoethyl)-1-naphthalenethiol (19). (+)(R)-1-(1-Naphthyl)ethylamine $(2 \mathrm{~g}, 11.7 \mathrm{mmol})$ was mixed with formic acid $(5 \mathrm{ml})$ at $0^{\circ} \mathrm{C}$. Formaldehyde $(37 \%$ aq., $5 \mathrm{ml}$ ) was added dropwise to the stirred reaction mixture. The resulting solution was refluxed overnight (or until $\mathrm{CO}_{2^{-}}$ evolution had ceased). The reaction mixture was acidified with conc. $\mathrm{HCl}$ (aq.) and washed with $\mathrm{Et}_{2} \mathrm{O}(2 \times 20 \mathrm{ml})$. The aqueous phase was made alkaline with sat. $\mathrm{NaOH}(\mathrm{aq})$. Extraction with $\mathrm{Et}_{2} \mathrm{O}(3 \times 50 \mathrm{ml})$ followed by drying over $\mathrm{Na}_{2} \mathrm{SO}_{4}$ and evaporation of the solvent in vacuo gave the crude $(R)$-1-(1-naphthyl)ethyl- $N$-dimethylamine which was purified by bulb-to-bulb distillation $\left(150^{\circ} \mathrm{C}, 1.5 \mathrm{~mm} \mathrm{Hg}\right)$ to yield $1.70 \mathrm{~g}(73 \%)$ of the pure product. $[\alpha]_{\mathrm{D}}^{19}=+67.3^{\circ}$ $\left(c=1.1\right.$ in $\left.\mathrm{CHCl}_{3}\right)$. Spectral data were in accordance with those reported earlier. ${ }^{21}$ This amine $(250 \mathrm{mg}, 1.25 \mathrm{mmol})$ was dissolved in dry $\mathrm{Et}_{2} \mathrm{O}(5 \mathrm{ml})$ and $t$-BuLi $(1.7 \mathrm{M}$ in pentane, $0.8 \mathrm{ml}$ ) was added dropwise at room temperature. The clear red solution was stirred for $1 \mathrm{~h}$ and then added via canula to a suspension of sublimed $\mathrm{S}_{8}(40 \mathrm{mg})$ in $\mathrm{Et}_{2} \mathrm{O}$ $(2 \mathrm{ml})$. The reaction mixture was stirred overnight. Conc. $\mathrm{HCl}$ (aq., $105 \mu \mathrm{l}$ ) was added. After $10 \mathrm{~min}$ all volatiles were removed in vacuo. The residue was dissolved in $\mathrm{CH}_{2} \mathrm{Cl}_{2}$ and filtered through a short silica column. Crystallization from $\mathrm{CH}_{2} \mathrm{Cl}_{2}$ and $\mathrm{Et}_{2} \mathrm{O}$ yielded $97 \mathrm{mg}$ (33\%) of $\mathbf{1 9}$ as pale yellow needle-shaped crystals which were washed with $\mathrm{Et}_{2} \mathrm{O}$ and dried in vacuo. $[\alpha]_{\mathrm{D}}^{18}=-65.2^{\circ} \quad\left(c=0.99\right.$ in $\left.\mathrm{CHCl}_{3}\right)$. $\mathrm{mp}=125^{\circ} \mathrm{C} .{ }^{1} \mathrm{H}$ NMR: $\delta 7.72(\mathrm{dd}, J=8.0 \mathrm{~Hz}, 1.6 \mathrm{~Hz}, 1 \mathrm{H})$, $7.62(\mathrm{~d}, J=8.6 \mathrm{~Hz}, 2 \mathrm{H}), 7.46(\mathrm{~d}, J=8.6 \mathrm{~Hz}, 1 \mathrm{H}), 7.40$ (ddd, $J=8.4,6.8,1.6 \mathrm{~Hz}, 1 \mathrm{H}), 7.26$ (ddd, $J=7.9,6.9,1.0 \mathrm{~Hz}, 1 \mathrm{H})$, 4.77 (q, J=6.9 Hz, 1H), 2.76 (s, 6H), 1.91 (d, 6.9 Hz, $3 \mathrm{H} 9)$. ${ }^{13}$ C NMR: $\delta$ 136.8, 131.4, 130.3, 129.0, 128.7, 126.8, 126.3, 125.1, 122.7, 118.4, 65.0, 40.5, 14.8. IR $\left(\mathrm{CHCl}_{3}\right): 3018$, 2952, 1614, 1589, 1476, 1220, 1210, 1080, $780 \mathrm{~cm}^{-1}$.

\section{General procedure for the arenethiolatocopper(I) catalyzed cross-coupling reactions with preformed copper catalysts}

Slow additions were carried out using a dropping funnel or a syringe pump under an atmosphere of dry, oxygen-free nitrogen.

Addition method A. The required amount of $(R)$ - or $(S)-\mathbf{1}$ was dissolved in toluene $(15 \mathrm{ml})$. The allylic substrate ( $1 \mathrm{mmol})$, dissolved in $\mathrm{Et}_{2} \mathrm{O}(15 \mathrm{ml})$, was added and the reaction mixture cooled to $0^{\circ} \mathrm{C}$. The Grignard reagent $(1.25 \mathrm{mmol})$ in $\mathrm{Et}_{2} \mathrm{O}(100 \mathrm{ml})$ was added dropwise over $2 \mathrm{~h}$. After complete addition, the reaction mixture was stirred for another $30 \mathrm{~min}$. The reaction mixture was quenched with $\mathrm{NH}_{4} \mathrm{Cl}$ and the internal standard $n$-dodecane was added. A GC-sample was taken and the reaction mixture was then extracted with $\mathrm{Et}_{2} \mathrm{O}(6 \times 25 \mathrm{ml})$ and the combined organic layers were dried $\left(\mathrm{MgSO}_{4}\right)$. The solvent was evaporated in vacuo and the crude product was purified by flash column chromatography with pentane as eluent.

Addition method $B$. The required amount of $(R)$ - or $(S)-\mathbf{1}$ was dissolved in toluene $(15 \mathrm{ml})$. The Grignard reagent $(1.25 \mathrm{mmol})$ was added to the catalyst and the reaction 
mixture was cooled to $0^{\circ} \mathrm{C}$. The allylic substrate $(1 \mathrm{mmol})$, dissolved in $\mathrm{Et}_{2} \mathrm{O}(100 \mathrm{ml})$, was added dropwise over $2 \mathrm{~h}$. After complete addition, the reaction mixture was stirred for another $30 \mathrm{~min}$. The work-up procedure was the same as described for method A.

Addition method $C$. The required amount of $(R)$ - or $(S)-\mathbf{1}$ was dissolved in toluene $(15 \mathrm{ml})$ and the reaction mixture was cooled to $0^{\circ} \mathrm{C}$. The Grignard reagent $(1.25 \mathrm{mmol})$, dissolved in $\mathrm{Et}_{2} \mathrm{O}(50 \mathrm{ml})$, and the allylic substrate $(1 \mathrm{mmol})$, dissolved in $\mathrm{Et}_{2} \mathrm{O}(50 \mathrm{ml})$, were added separately at the same time to the catalyst solution in $2 \mathrm{~h}$. After complete addition, the reaction mixture was stirred for another $30 \mathrm{~min}$. The work-up procedure was the same as described for method A.

General procedures for the arenethiolatocopper(I) catalyzed cross-coupling reactions with catalysts prepared in situ

Addition of the Grignard reagent was carried out using a syringe pump under an atmosphere of dry, oxygen-free argon.

The chiral arenethiol ligand $(0.085 \mathrm{mmol})$ was dissolved in $\mathrm{Et}_{2} \mathrm{O}(45 \mathrm{ml})$ and the solution was cooled to $-78^{\circ} \mathrm{C}$. A solution of $n$-BuLi in hexanes $(1.6 \mathrm{M}, 75 \mu \mathrm{l})$ was added and the mixture was stirred for $10 \mathrm{~min}$. The solution was warmed to $0^{\circ} \mathrm{C}$ and copper(I) iodide $(0.085 \mathrm{mmol})$ was added. (In an alternative procedure, which gave equal results, the solution of the lithium arenethiolate was added to a suspension of $\mathrm{CuI}$ in $\mathrm{Et}_{2} \mathrm{O}$.) The solution was stirred at $0^{\circ} \mathrm{C}$ for another $30 \mathrm{~min}$ and then the allylic substrate $(0.549 \mathrm{mmol})$, dissolved in $\mathrm{Et}_{2} \mathrm{O}(5 \mathrm{ml})$, was added by syringe. The Grignard reagent ( 1.25 equiv. of a solution in $\mathrm{Et}_{2} \mathrm{O}$ ) was added dropwise over $2 \mathrm{~h}$. After complete addition, the reaction mixture was stirred for $1 \mathrm{~h}$. The reaction was quenched by adding a $2 \mathrm{M}$ solution of $\mathrm{HCl}$ $(10 \mathrm{ml})$. The organic layer was separated and the aqueous layer was extracted three times with a 1:1 mixture of pentane and ether. The combined organic layers were washed with a saturated solution of $\mathrm{NaCl}$ and dried $\left(\mathrm{MgSO}_{4}\right)$. The substitution products were purified by flash column chromatography with pentane as eluent.

\section{Characterization of the $\gamma$-substitution products}

3-(Cyclohexyl)heptene (5). The spectral data were in accordance with the literature. ${ }^{4 \mathrm{~d}}$

((3-Cyclohexyl)-1-buten-4-yl)trimethylsilane (7). ${ }^{1} \mathrm{H}$ NMR: $\delta 5.57(\mathrm{ddd}, J=16.8,10.3,6.5 \mathrm{~Hz}, 1 \mathrm{H}), 4.90(\mathrm{dd}, J=4.1$, $2.2 \mathrm{~Hz}, 1 \mathrm{H}), 4.86(\mathrm{dd}, J=10.6,2.1 \mathrm{~Hz}, 1 \mathrm{H}), 1.98(\mathrm{~m}, 1 \mathrm{H})$, $1.75(\mathrm{~m}, 5 \mathrm{H}), 1.10(\mathrm{~m}, 6 \mathrm{H}), 0.69(\mathrm{dd}, J=14.6,4.1 \mathrm{~Hz}, 1 \mathrm{H})$, $0.56(\mathrm{dd}, J=14.7,10.0 \mathrm{~Hz}, 1 \mathrm{H}),-0.03$ (s, 9H). ${ }^{13} \mathrm{C}$ NMR: $\delta$ 143.22, 113.67, 46.07, 44.60, 30.97, 29.24, 26.86, 26.83, 19.58, -0.50. MS: $210\left(\mathrm{M}^{+}, 0.2\right), 195$ (34), 167 (15), 136 (10), 73 (100).

3-(Phenyloxy)methyl-1-heptene (9). The spectral data were in accordance with the literature. ${ }^{14 \mathrm{~b}}$

3-Phenyl-1-heptene (11). The e.e. was determined by GC.
An e.e. of $30 \%$ corresponds to $[\alpha]_{\mathrm{D}}^{\mathrm{rt}}=-11.2^{\circ}(c=1.25$ in $\left.\mathrm{CHCl}_{3}\right)$. The spectral data were in accordance with the literature. $^{6 \mathrm{e}}$

3-Cyclohexyl-4-methyl-1-pentene (20). ${ }^{1} \mathrm{H}$ NMR: $\delta 5.51$ (ddd, $J=17.0,10.2,7.1 \mathrm{~Hz}, 1 \mathrm{H}), 5.02(\mathrm{dd}, J=10.3,2.6 \mathrm{~Hz}$, $1 \mathrm{H}), 4.87(\mathrm{~m}, J=17.0,2.5 \mathrm{~Hz}, 1 \mathrm{H}), 1.68(\mathrm{~m}, 6 \mathrm{H}), 1.46(\mathrm{~m}$, 1H), $1.15(\mathrm{~m}, 6 \mathrm{H}), 0.85(\mathrm{~d}, 3 \mathrm{H}, J=6.9 \mathrm{~Hz}), 0.78(\mathrm{~d}, 3 \mathrm{H}$, $J=6.6 \mathrm{~Hz}) .{ }^{13} \mathrm{C}$ NMR: $\delta$ 139.25, 116.26, 57.18, 38.54, $32.09,30.19,27.52,27.14,27.09,27.02,21.87,21.40$. MS: $166\left(\mathrm{M}^{+}, 0.3\right), 138$ (21), 123 (12), 95 (14), 81 (100), 67 (90), 55 (64).

3-Cyclohexyl-5-methyl-1-hexene (22). ${ }^{1} \mathrm{H}$ NMR: $\delta 5.53$ (ddd, $J=17.0,10.0,6.8 \mathrm{~Hz}, 1 \mathrm{H}), 4.96(\mathrm{dd}, J=10.2,2.2 \mathrm{~Hz}$, 1H), 4.90 (ddd, $J=17.0,2.5,0.8 \mathrm{~Hz}, 1 \mathrm{H}), 1.86$ (m, 1H), 1.60 $(\mathrm{m}, 6 \mathrm{H}), 1.10(\mathrm{~m}, 8 \mathrm{H}), 0.87(\mathrm{~d}, J=6.6 \mathrm{~Hz}, 6 \mathrm{H}) .{ }^{13} \mathrm{C}$ NMR: $\delta$ 141.65, 114.45, 47.76, 42.16, 41.17, 39.01, 33.36, 31.26, 29.68, 26.82, 26.35, 22.63, 21.55. MS: $180\left(\mathrm{M}^{+}, 0.1\right), 152$ (14), 124 (16), 96 (40), 81 (85), 67 (84), 55 (100).

3-Phenyl-4-methyl-1-pentene (24). The spectral data were in accordance with the literature. ${ }^{10 d}$ The e.e.'s obtained by GC were in agreement with the e.e.'s obtained after comparison of the optical rotation with the literature value $\left([\alpha]_{\mathrm{D}}^{25}=-95.5^{\circ}\left(c=1.5\right.\right.$ in $\left.\mathrm{CHCl}_{3}\right)$ corresponds to $78 \%$ e.e. for $(R)-24){ }^{10 \mathrm{~d}}$

\section{Acknowledgements}

Financial support from the Netherlands Organization for Scientific Research (NWO), the Royal Swedish Academy of Sciences, The Swedish Foundation for Strategic Research and the Swedish Natural Science Research Council is gratefully acknowledged.

\section{References}

1. Transition Metals for Organic Synthesis, Beller, M., Bolm, C. Eds.; Wiley VCH: Weinheim, 1998.

2. (a) Posner, G. H. Org. React. 1975, 22, 253. (b) Lipshutz, B. H.; Sengupta, S. Org. React. 1992, 41, 135. (c) Lipshutz, B. H. In Organometallics in Synthesis; Schlosser, M., Ed.; Wiley: Chichester, 1994; Chapter 4, p 283. (d) Organocopper Reagents. A Practical Approach; Taylor, R. J. K., Ed.; Oxford University Press: Oxford, 1994.

3. Magid, R. M. Tetrahedron, 1980, 36, 1901 and references cited therein.

4. (a) Bäckvall, J.-E.; Sellén, M. J. Chem. Soc. Chem. Commun. 1987, 827. (b) Bäckvall, J.-E.; Sellén, M.; Grant, B. J. Am. Chem. Soc. 1990, 112, 6615. (c) Bäckvall, J.-E.; Persson, E. S. M.; Bombrun, A. J. Org. Chem. 1994, 59, 4126. (d) Persson, E. S. M.; Bäckvall, J.-E. Acta Chem. Scand. 1995, 49, 899.

5. (a) Trost, B. M.; Klun, T. P. J. Org. Chem. 1980, 45, 4257. (b) Yamamoto, Y.; Yamamoto, S.; Yatagai, H.; Maruyama, K. J. Am. Chem. Soc. 1980, 102, 2318. (c) Gallina, C. Tetrahedron Lett. 1982, 23, 3093. (d) Caló, V.; Lopez, L.; Carlucci, W. F. J. Chem. Soc. Perkin Trans. 1 1983, 2953. (e) Julia, M.; Righini-Tapie, A.; Verpeaux, J.-N. Tetrahedron 1983, 39, 3283. (f) Kang, J.; Lee, W. K. J. Org. Chem. 1984, 49, 1838. (g) Curran, D. P.; Chen, 
M.-H.; Leszczweski, D.; Elliot, R. L.; Rakiewicz, D. M. J. Org. Chem. 1986, 51, 1612.

6. (a) Sekiya, K.; Nakamura, E. Tetrahedron Lett. 1988, 29, 5155. (b) Arai, M.; Lipshutz, B. H.; Nakamura, E. Tetrahedron 1992, 48, 5709. (c) Arai, M.; Kawasuji, T.; Nakamura, E. J. Org. Chem. 1993, 58, 5121. (d) Yanagisawa, A.; Nomura, N.; Noritake, Y.; Yamamoto, H. Synthesis 1991, 1130. (e) Yanagisawa, A.; Nomura, N.; Yamamoto, H. Tetrahedron 1994, 50, 6017. (f) Underiner, T.; Goering, H. L. J. Org. Chem. 1991, 56, 2563, and preceding papers in this series. (g) Ibuka, T.; Taga, T.; Habashita, H.; Nakai, K.; Tamamura, H.; Fujii, N.; Chounan, Y.; Nemoto, H.; Yamamoto, Y. J. Org. Chem. 1993, 58, 1207. (h) Dieter, R. K.; Velu, S. E.; Nice, L. E. Synlett 1997, 1114. (i) Smitrovich, J. H.; Woerpel, K. A. J. Am. Chem. Soc. 1998, 120, 12998. (j) Mechelke, M. F.; Wiemer, D. F. J. Org. Chem. 1999, 64, 4821.

7. For a review, see for example: (a) Rossiter, B. E.; Swingle, N. M. Chem Rev. 1992, 92, 771. (b) Feringa, B. L.; de Vries, A. H. M. In Advances in Catalytic Processes; Doyle, M. P., Ed.; JAI: Greenwich, CT, 1995; Vol. 1, p 151. (c) Krause, N.; Gerold, A. Angew. Chem., Int. Ed. Engl. 1997, 36, 186. (d) Krause, N. Angew. Chem., Int. Ed. 1998, 37, 283.

8. (a) Lambert, F.; Knotter, D. M.; Janssen, M. D.; van Klaveren, M.; Boersma, J.; van Koten, G. Tetrahedron: Asymmetry 1991, 2, 1097. (b) van Klaveren, M.; Lambert, F.; Eijkelkamp, D. J. F. M.; Grove, D. M.; van Koten, G. Tetrahedron Lett. 1994, 35, 6135. (c) van Koten, G. Pure Appl. Chem. 1994, 66, 1455.

9. For some recent examples, see: (a) Knöbel, A. K. H.; Escher, I. H.; Pfaltz, A. Synlett. 1997, 1429. (b) de Vries, A. H. M.; Hof, R. P.; Staal, D.; Kellogg, R. M.; Feringa, B. L. Tetrahedron: Asymmetry 1997, 8, 1539. (c) Seebach, D.; Jaeschke, G.; Pichota, A.; Audergon, L. Helv. Chim. Acta 1997, 80, 2515. (d) Keller, E.; Maurer, J.; Naasz, R.; Schader, T.; Meetsma, A.; Feringa, B. L. Tetrahedron: Asymmetry 1998, 9, 2409. (e) Mori, T.; Kosaka, K.; Nakagawa, Y.; Nagaoka, Y.; Tomioka, K. Tetrahedron: Asymmetry 1998, 9, 3175. (f) Kanai, M.; Nakagawa, Y.; Tomioka, K. Tetrahedron 1999, 55, 3831. (g) Kanai, M.; Nakagawa, Y.; Tomioka, K. Tetrahedron 1999, 55, 3843. (h) Yan, M.; Chan, A. S. C. Tetrahedron Lett. 1999, 40, 6645.

10. (a) Denmark, S. E.; Marble, L. K. J. Org. Chem. 1990, 55,
1984. (b) Caló, V.; Fiandanese, V.; Nacci, A. Trends in Organic Chemistry 1993, 4, 479. (c) Caló, V.; Fiandanese, V.; Nacci, A.; Scilimati, A. Tetrahedron 1994, 50, 7283. (d) Caló, V.; Nacci, A.; Fiandanese, V. Tetrahedron 1996, 52, 10799. (e) Gais H.-J.; Müller, H.; Bund, J.; Scommoda, M.; Brandt, J.; Raabe, G. J. Am. Chem. Soc. 1995, 117, 2453. (f) Rakotoarisoa, H.; Perez, R. G.; Mangeney, P.; Alexakis, A. Organometallics 1996, 15, 1957.

11. van Klaveren, M.; Persson, E. S. M.; del Villar, A.; Grove, D. M.; Bäckvall, J.-E.; van Koten, G. Tetrahedron Lett. 1995, 36, 3059.

12. Dübner, F.; Knochel, P. Angew. Chem., Int. Ed. 1999, 38, 379.

13. (a) Knotter, D. M.; van Koten, G.; van Maanen, H. L.; Grove D. M.; Spek, A. L. Angew. Chem. 1989, 101, 351. Angew. Chem., Int. Ed. Engl. 1989, 28, 341. (b) Knotter, D. M.; van Maanen, H. L.; Grove, D. M.; Spek. A. L.; van Koten, G. Inorg. Chem. 1991, 30, 3309. (c) Knotter, D. M.; Janssen, M. D.; Grove, D. M.; Smeets, W. J. J.; Horn. E.; Spek, A. L.; van Koten, G. Inorg Chem. 1991, 30, 4361. (d) Janssen, M. D.; Grove, D. M.; van Koten, G. Progress in Inorganic Chemistry 1997, 46, 97.

14. (a) van Klaveren, M.; Persson, E. S. M.; Grove, D. M.; Bäckvall, J.-E.; van Koten, G. Tetrahedron Lett. 1994, 35, 5931. (b) Persson, E. S. M.; van Klaveren, M.; Grove, D. M.; Bäckvall, J.-E.; van Koten, G. Chem. Eur. J. 1995, 1, 351.

15. Bäckvall, J.-E.; Sellén, M.; Nyström, J. E. Acta Chem. Scand. 1988, B42, 397.

16. Tseng, C. C.; Paisley, S. D.; Goering, H. L. J. Org. Chem. 1986, 51, 2884.

17. (a) Rijnberg, E.; Jastrzebski, J. T. B. H.; Janssen, M. D.; Boersma, J.; van Koten, G. Tetrahedron Lett. 1994, 35, 6521. (b) Rijnberg, E.; Hovestad, N. J.; Kleij, A. W.; Jastrzebski, J. T. B. H.; Boersma, J.; Janssen, M. D.; Spek, A. L.; van Koten, G. Organometallics 1997, 16, 2847.

18. Karlström, A. S. E.; van Koten, G. Unpublished results.

19. (a) Zhou Q.; Pfaltz, A. Tetrahedron Lett. 1993, 34, 7725. (b) Zhou Q.; Pfaltz, A. Tetrahedron 1994, 50, 4467.

20. (a) Watson, S. C.; Eastman, J. F. J. Organomet. Chem. 1967, 9, 165. (b) Bergbreiter, D. E.; Pendergrass, E. J. Org. Chem. 1981, 46, 219.

21. Ebden, M. R.; Simpkins, N. S. Tetrahedron 1998, 54, 12923. 